\title{
Bustans in the Historic Buildings of Cairo: Bayt Yakan and its surrounding Sustainable Neighborhood Alaa El-Habashi ${ }^{1}$, Yassmen Hesham ${ }^{1,2^{*}}$, and Rawan Darwas ${ }^{1}$
}

\author{
${ }^{1}$ Architectural Engineering Department, Faculty of Engineering, Menoufia University, \\ Shebin El-Kom, Egypt. \\ ${ }^{2}$ Ph.D. Candidate, Architectural Engineering Department, Faculty of Engineering, \\ Menoufia University, Shebin El-Kom, Egypt. \\ *(Corresponding author: yassmen.hisham@gmail.com)
}

\begin{abstract}
Courtyard houses in historic cities of arid areas have roles in regulating the climatic conditions. Those buildings are located within the hearts of urban blocks to expand their ecological impact on their surroundings. Resided by the elites, they were of particular positioning within their neighborhoods to make their courtyards for community interactions. The greeneries, the water, and the serene furniture were elements made those courtyards as little oases in the city's fabric. Unfortunately, most of those houses are demolished or deserted in bad conditions; a fact that disrupted their climatic and social roles. This research explores the revitalization one of those houses, to introduce the means to re-activate the climatic role and the passivity of the building from one side, and to re-establish social links between the courtyard and the community. The focus is on a recent initiative to establish a "Bustan" in Bayt Yakan that mimics the historic garden usually annexed to the northern of the courtyards. The Bustan is designed on the parameters of the contemporary state of the house. It reinvigorates the roles of greeneries and regenerating the local economy. It involves the community in the process of designing, planting, and maintaining it to encourage them to start small gardens in their houses and that is a positive step to adopt the UNESCO's HUL approach to revive the heritage values of Historic Cairo. The design also attempts to balance between several aspects such as: selecting suitable plants, harmonizing with the historic surroundings, and partnering with the community.
\end{abstract}

Keywords: Bayt Yakan; Historic buildings; climate performance; greeneries; Historic Urban Landscape.

\section{Gardens of Islamic Traditional Houses}

The design of traditional houses in the Islamic World is influenced by a wide range of social, religious, and environmental factors. The courtyard is considered as the main core of the house around which most of the rooms are arranged. Room windows and openings are giving to the courtyard and its garden (bustan in Arabic). The courtyard size, orientation, and shape prevailed onto multiple variables, among which the immediate urban surrounding. It usually includes a well, a fountain, and flanked by a small garden. In most cases, the courtyard was rectangular in shape (Figure 1). It was considered not only a gathering place for the residents of the house but a semiprivate space for the surrounding community and the visitors of the hara where the building is located. More importantly, the courtyard is a mean of ventilation, natural lighting. It separates and controls accesses of the inhabitants and the guests. The trees, plants that existed in the bustan associated with the courtyard works with the central fountain to purify and humidify the air and provide the indoor spaces with thermal comfort throughout a well-calculated airflow throughout the openings of the flanking halls and rooms [1]. Therefore, the gardens and its landscape elements within the courtyard play a very important role in controlling and improving the microclimatic beside the economic value it entails through the agricultural products. It also provides the members of the community with a shaded space with the best climatic conditions and seating areas for them to interact, thus plays an important social role.

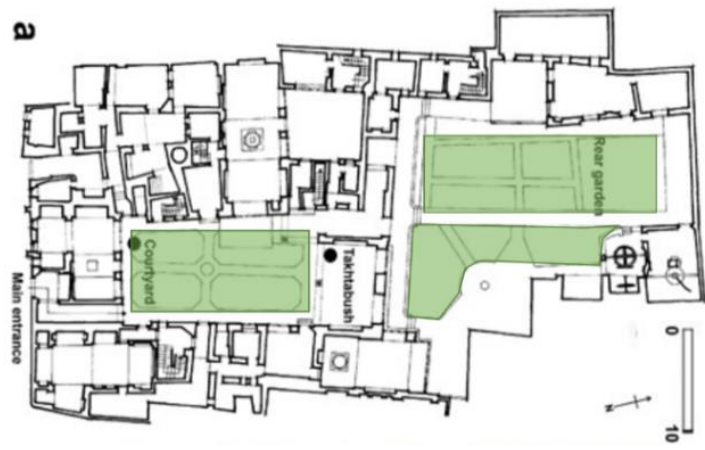

Figure 1: Al- Suhaymi courtyards and bustan [Source: Modified from [1]] 


\section{The Importance of House Gardens}

Courtyard greenery, plants, and trees, that are growing in the courtyard creates a miniature oasis in the heart of the house to help in providing the required thermal comfort [2] by interacted with other existing architectural and built elements, such as 'Takhtabush' (hall), and shukhshaykha (lantern). This creates an air-cooling current between the shaded and humid interior (high pressure) and the sunny drier open courtyard (low pressure). Due to the difference in pressure [1], wind speed, and dimensions of the openings, the cool air is being redistributed. (Figure 2).

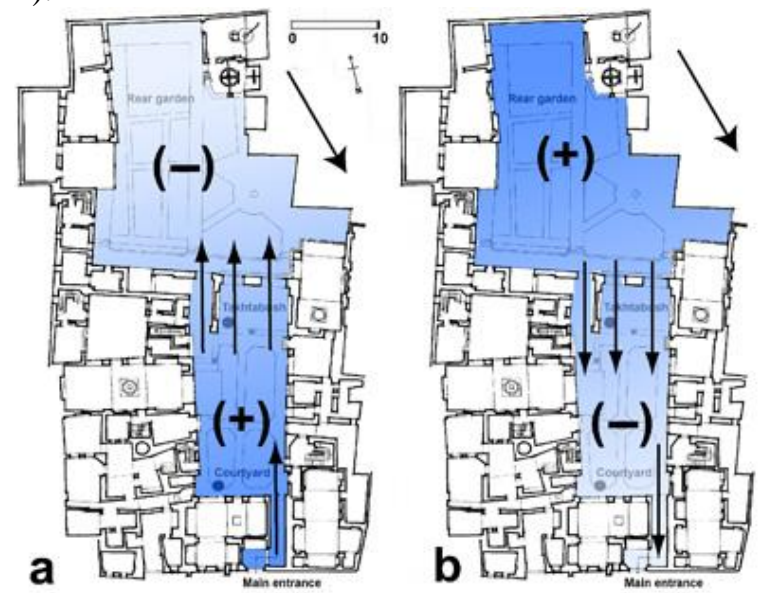

Figure 2: Al- Suhaymi house garden and the recommended air circulation according to the difference in pressure air [Source: [1]]

The bustan also absorbs sun radiant heat and prevents reflecting it into the interior spaces, as opposed to the quantity of heat radiation in the case of paving or dry earth. There are several parameters involved in making the bustan more efficient in its cooling effect, among those are the trees' density, the distribution of the trees, and the expected shades resulted from surrounding high elements [3]. The effect of trees and the greeneries are as following:

- decrease the direct radiation of sunbeams in courtyards,

- cast shadows on walls, windows, and openings of buildings,

- decrease the temperature in and around the building,

- increase the humidity in dry regions,

- decrease and filter the dust blown in winds,

- decrease the undesirable wind speed that reached the courtyard building.

Nowadays most of the bustans of traditional courtyards were either deserted or built upon. In rare cases if they still exist, the disfiguration of their surroundings, especially with the rise of buildings, is blocking the air to flow in and is invading their privacies. Bayt $\mathrm{Al}-$ Suhaymi and Bayt Al-Razzaz in Historic Cairo are two traditional houses with courtyards that still having their inner garden (bustan) as shown in Figure 3 and Figure 4. Those, however, are mostly deserted. Most of the other courtyard houses have lost their bustans and accordingly they lost their social, environmental, and climatic roles.

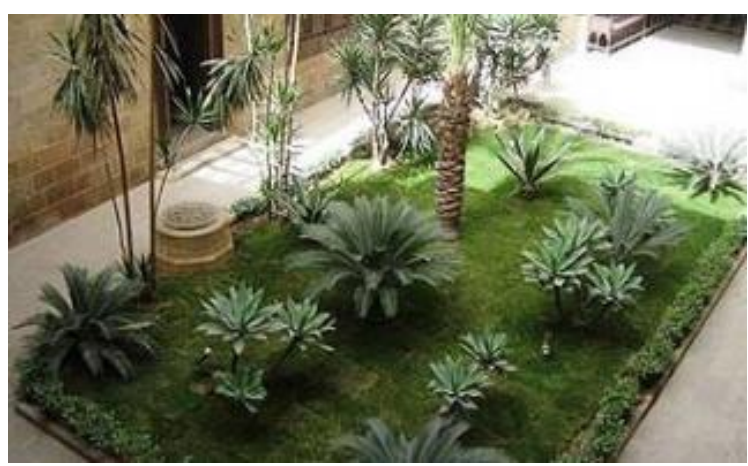

Figure 3: The existing inner garden of Bayt AlSuhaymi. [Source: [4]]

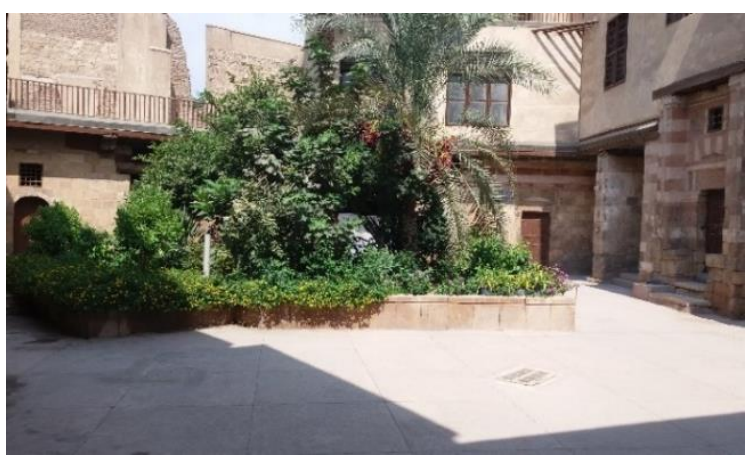

Figure 4: Exiting inner garden of the eastern section of Bay Al-Razzaz. [Source: Researchers]

While the losses of those gardens are accelerating, international charters as "The Valletta for the Preservation and Management of Historic Cities, Towns and Urban Areas" are being published to assure that all approved interventions must ensure "respect for the values of tangible and intangible heritage, as well as the quality of life of the local community..." The Valletta and other ICOMOS charter seek to highlight and preserve the environmental values of the targeted historic areas so that they would integrate into the contemporary life of their inhabitants without compromising their values. They appear to avoid the destruction of natural resources, wasting energy, disrupting the balance of natural cycles, and protecting historical cities from the effects of risks and recurring disasters. The ICOMOS, as the technical advisor of UNESCO, recognizes such demands in the management of historic context and adopted them on (28, November 2011, Valletta) [5], [6]. The project presented in this paper takes those international mandates into consideration beside the wish to provide 
pleasant and socially agreeable greeneries in the semipublic space of a particular courtyard house, Bayt Yakan.

\section{Bayt Yakan and its Bustan}

Bayt Yakan is a traditional courtyard house in the alDarb al-Ahmar administrative sector of Historic Cairo. Similar to at all its counterparts, it suffered from major detrimental intrinsic and intrinsic modifications. Throughout the last eighty years, more specifically since from the last issued cadastral map of 1937, there have been many significant modifications to the original state of the building compared to its current 2020 state. The 1937 cadastral map indicates that the original courtyard of the house included a large garden (bustan) in its northern side, helping to direct and filter the wind before it reaches the building, and a water fountain to help provide the right humidity percentage. The bustan no longer exists as it was built over as shown in the 2020 map. (Figure 5) The vanished bustan of Bayt Yakan is not an exception; many other surrounding ones also disappeared, especially the large one that existed in Ibrahim Pasha Yakan House located towards the east. Surely, those modifications have negatively affected the traditional environmental system of the neighborhood, as well as of the climatic conditions of the built fabric.

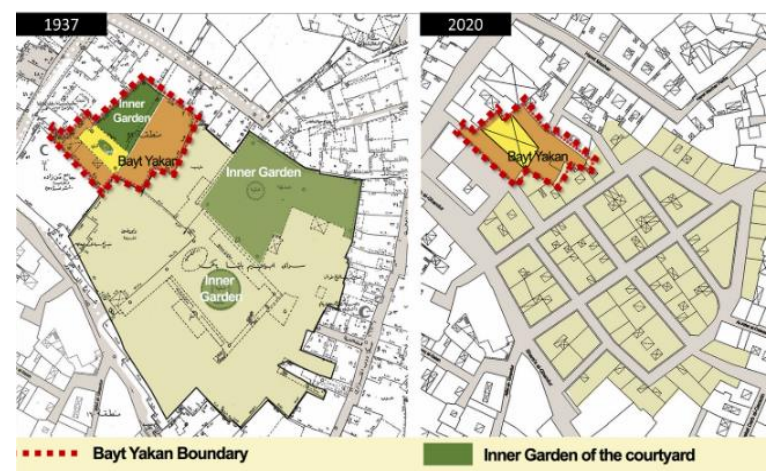

Figure 5: Left map shows Bayt Yakan with its inner garden as it is in the 1937 cadastral map, the right map is for Bayt Yakan nowadays in 2020 after the removing of is garden. [Source: Researchers]

The above analyses were the reasons to consider restoring the bustan of Bayt Yakan once more, within the allowed space and functional parameters. The hope is to restore some of the eco-system that was lost, in addition to integrating the local community once more in the courtyard, the semi-public space that all the residents are striving for. For that to be achieved, it was planned to be implemented in different stages so that it would gain the required social momentum and to better integrate the community members in the process so that their belonging to the area and their new semi-public space would rise.

\section{Restoring bustan Bayt Yakan}

Reusing a historical house, which was once abandoned and left for the sheep to wander in, after being once an icon, was the approach the new owners opted for. Once available, the surrounding community was quickly integrated into the activities offered in the house and has started to claim back their semi-public space that was long-awaited for. [7] The bustan was an inevitable demand for the rising communal integration and remuneration for the community's active devotion in the neighborhood development and enhancement. Bayt Yakan became not only a restored historical house, but also a hub for the community to interact, learn from, and plan for future neighborhood developments. The bustan was also a nucleus of a large plan to restore the greeneries within the historic city. [8] The concept of having a small garden containing greenery and vegetation can not only help the climatic conditions of the house but also if adopted into the historic city scale can enhance the overall ecosystem of the urban fabric.

Bayt Yakan has been an icon in historic Cairo of creating a space for the community where they can celebrate, learn, and have all their gathering in. By being this icon, it started to teach the public many values about the benefits of heritage conservation, and the means to live, enjoy, and creatively develop this heritage for the benefits of the local community. Bayt Yakan would not exist without the help and support of the community because by creating this special bond they are the ones who want to see it flourishing and continuously advancing. This was indeed the spirit of forming the sense of the traditional hara once again.

The courtyard of Bayt Yakan house was used in gatherings, celebrations, and workshops but always been missing one of its essential characteristics that already existed when first built, the bustan. Besides, the following are the different reasons for the reestablishment of the bustan:

a) Environmental aspect

Based on a master's degree study issued from the Faculty of Engineering of Menoufia University in 2019 about the assessment of the environmental performance for the courtyard houses, among which Bayt Yakan was selected as a case study, [9] the removal of the garden had negative effects on the indoor microclimatic conditions. The study recommended restoring the bustan in the courtyard in Bayt Yakan to enhance the environmental aspects and provide a suitable thermal comfort for users of the house.

\section{b) Economical aspect}

Another academic master-degree study issued in 2019 in BTU Cottbus/Alexandria University indicated that adopting green corridors strategy in Al- Darb Al-Ahmar in general, and in the surrounding of Bayt Yakan in 
specific, would lead to positive socio-economic, environmental, and cultural results for them to be pillars of the prospective Sustainable Development in the historical context. [8] In that respect, al-Bustan is established to be a seed for achieving such targets, similar to the developments that took place in Shibuya in Japan which has exploited the green corridors and made its economy based mainly on the production of honey within the green corridors. [7] Plants' genres and species of Bayt Yakan bustan were well chosen for them to be used medicinally and culinary by the local community. This will surely have its economic impact because of using most of these plants and not just having them for their aesthetic values.

c) Social aspect

A workshop with the community has been conducted before creating the garden and resulting in an agreement by all members of the community that they are in need of a bustan in the courtyard with specific plant kinds. Involved community members as well as others are invited to use it and also transplant seedlings from it in their rooftops and balconies. The economic benefits would then prevail and augment in the hope that it would create a new basis for future economic boosting in the area, similar to what took place in Shibuya.

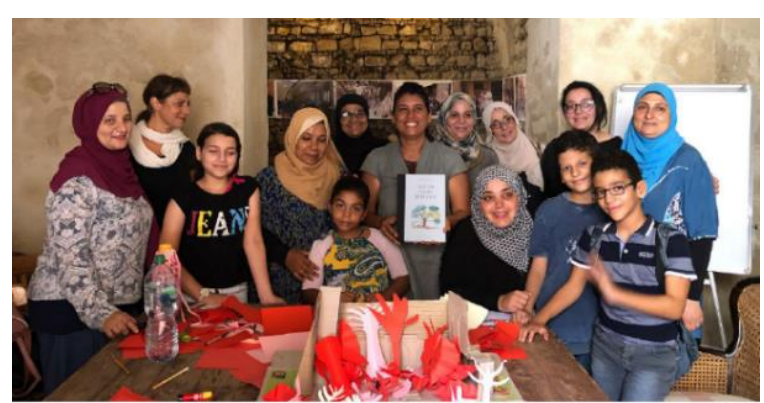

Figure 6: The community of Bayt Yakan in the workshop of "Bustan Bayt Yakan". [Source: Researchers].

\section{The design of the Bustan}

Bustan is a collaborative project of creating a pocket garden in Historic Cairo in Al Darb AL Ahmar, which is established in Bayt Yakan Courtyard. The Bustan is designed by Bureau Lada, who is an architect in Amsterdam, Netherlands, and funded by the Dutch Creative Industries Fund. The garden includes edible and medicinal plants, herbs, Moringa tree and seating benches for different activities and community interactions. The garden could be considered as a 'starting' point for the establishment of an ecological, social, and economical network within Historic Cairo . This garden is relatively small, including essential elements in the design process. (Figure 7) The concept of the design is based on the following parameters: [10]

\subsection{Garden Zone}

The bustan is designed to be adjacent to the wall with an old gate which will be activated as the new entrance for future, and that was taken in the design requirements of "al Bustan".

\subsection{Viewlines}

The design should articulate a route throughout the courtyard and creating the 'garden front'. The entrance to a historic gate that was reconstructed along the chosen wall is not immediately revealed; creating a natural movement in the courtyard to enhance the circulation.
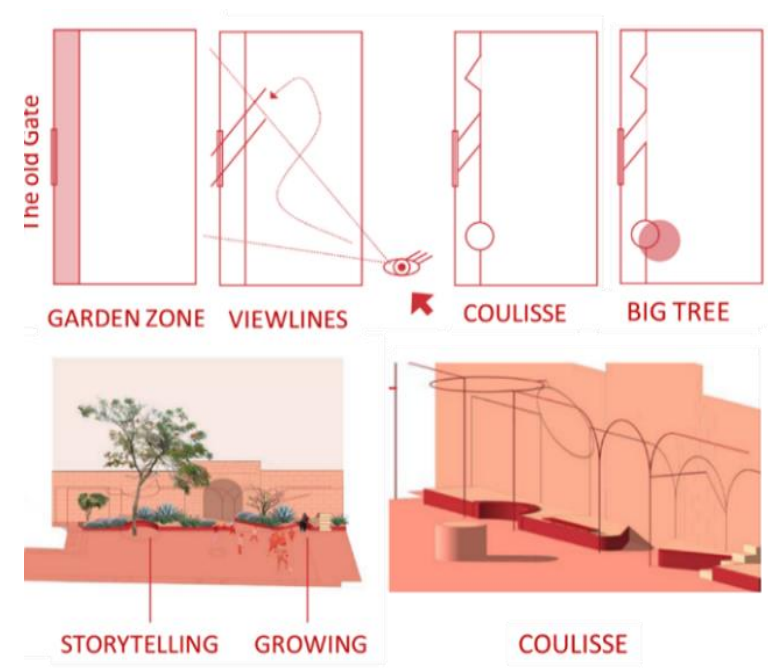

Figure 7: The essential elements of "Al Bustan" design. [Source: [10]]

\subsection{Coulisse}

The design provides places to stay in the garden in carved in-between the metal frame coulisse and the garden. Coulisse serves to fix the curtain to provide shade, and for climbing plants to grow adding depth to the garden.

\subsection{Big Tree}

A big tree was envisioned to provide character and shade. Few options are proposed to choose the best fit for the historic surrounding, its use, and how it can fit with the community. A moringa tree, as stated above was selected.

\subsection{Storytelling}

The design is offering a round seating bench next to the big Moringa tree for many activities like storytelling, learning, observing, and creating a closed space to make the visitors feel the intimacy of the garden and interact with it. 


\subsection{Growing}

The design offers space and benches for transplanting existing plants which are of great value to the community which they, themselves planted. In addition to those basic parameters of the design concept, several other considerations have been considered in selecting the location and implementation of the bustan of Bayt Yakan.

\subsection{Courtyard Functions}

The wish-list of the spatial and vegetative/programmatic characteristics of the bustan is ambitious and high. This was achieved through a clear, simple, and humble scale garden. For that reason, the approach aims to provide maximum vegetation possible in the courtyard that was already reduced in size as explained above. The two vegetation areas planned an existing wall further accentuated the value of a historic gate whose stones were saved from the debris of a demolished building and reconstructed there. This gate is provisioned to provide passage towards other spaces in Bayt Yakan. The long bench is positioned at the shady side of the courtyard.

\subsection{Shadowing}

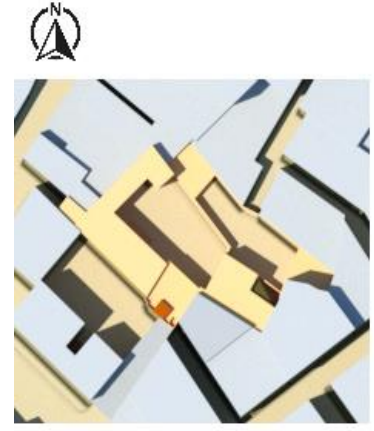

$10 \mathrm{AM}$

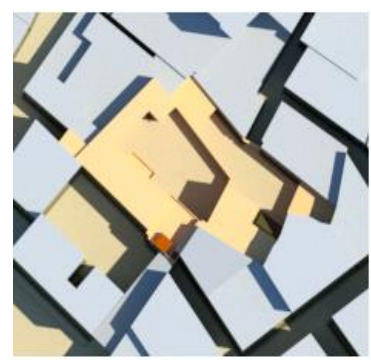

01 PM

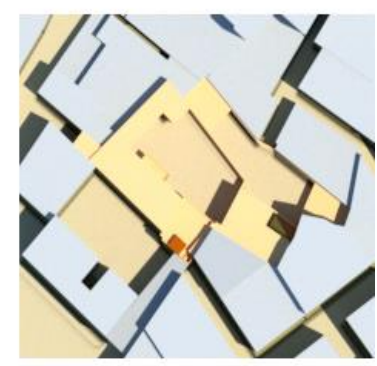

$11 \mathrm{AM}$

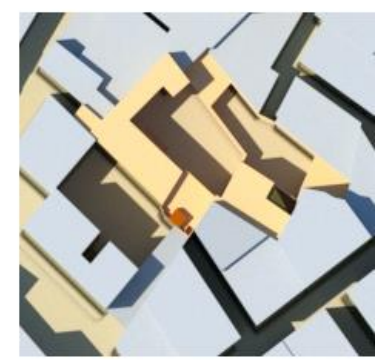

02 PM
Figure 8: Shadow analysis for Bayt Yakan courtyard without Garden on $21^{\text {st }}$ June

[Source: Simulated by Researchers]

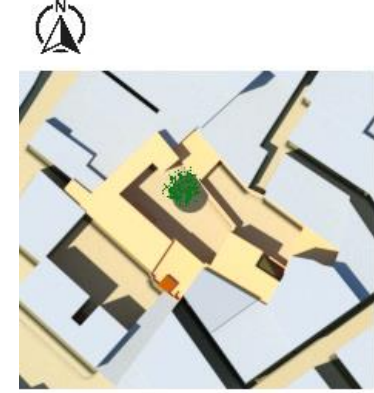

$10 \mathrm{AM}$

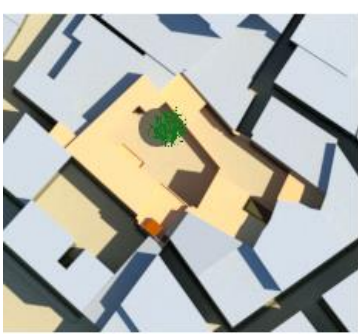

01 PM

Figure 9: Shadow analysis for Bayt Yakan courtyard included a big tree and garden on $21^{\text {st }}$ June

[Source: Simulated by Researchers]

The Shadow analysis in the courtyard of Bayt Yakan proves that the selected area for the bustan has a positive effect in increasing shaded areas. This effectiveness was assessed virtually when the sun is in its utmost exposure and with maximum solar radiation during the 21 st of June of each year. The courtyard without its bustan is mostly not shaded, while with its bustan and its big tree the shaded area is increased. (See Figure 9). It was recommended to implement a pocket garden to reach the maximum shadowing and provide the users with extreme thermal comfort as possible as an initial step for improving the microclimate conditions.

\subsection{Benches and Seating Areas}

It was necessary for the bustan to provide the users of the courtyard with seating areas. (Figure 10) It was important to offer seating areas that replace the one that existed before the bustan, and meanwhile, improves human integration with green elements of the bustan. Benches were carefully positioned and designed to offer such parameters. (Figure 11) In addition, one of three offered benches was designed to be extendable vertically to turn into a table that can be used for either transplanting or serving during events. The design of the benches with its teak wood helps to enhance the community activities inside the courtyard and encourage the users and community to be more interactive with the bustan and each other. (Figure 12) 


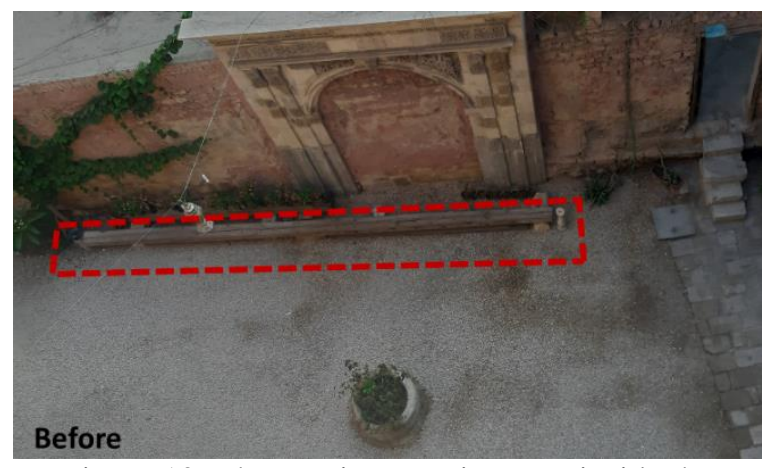

Figure 10: The previous seating area inside the courtyard [Source: Researchers]

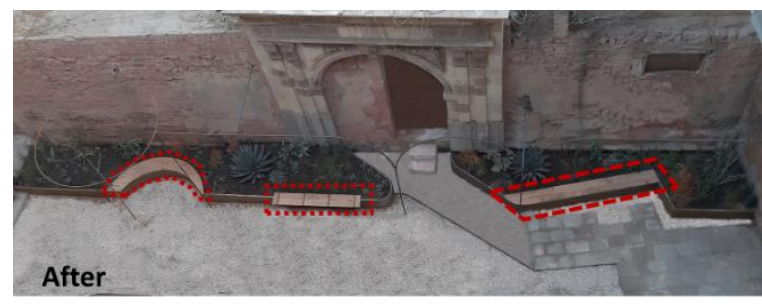

Figure 11: New Benches within the bustan for seating [Source: Researchers]
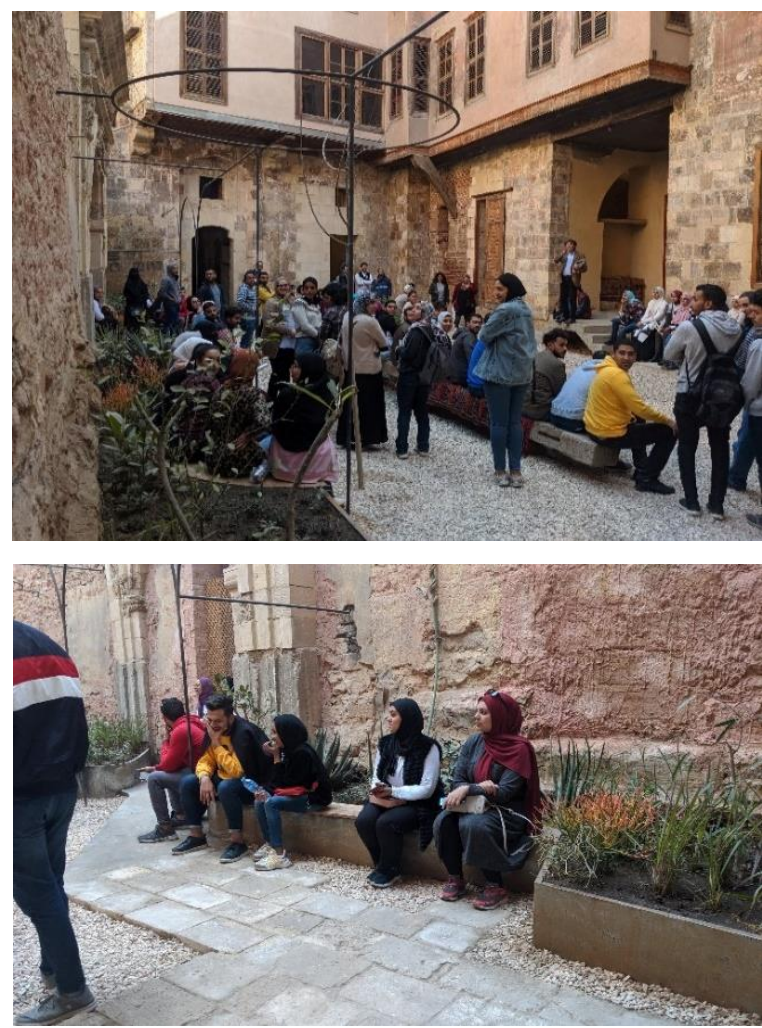

Figure 12: The community interact with the bustan using the benches in events and different activities.

[Source: Researchers]

\subsection{Users Mobility}

The bustan has a dual act: it is a transition phase between multiple spaces, and it is used in itself to host and encourage gatherings. Considering the movement within the courtyard is, therefore, an essential aspect of design. While the movement towards the different entrance gates located in the courtyard was enhanced given hierarchal levels, the benches distributed along the bustan are so inviting and offer different levels of intimacy and privacy to hosts diverse kinds of meetings and gatherings. (Figure 13)
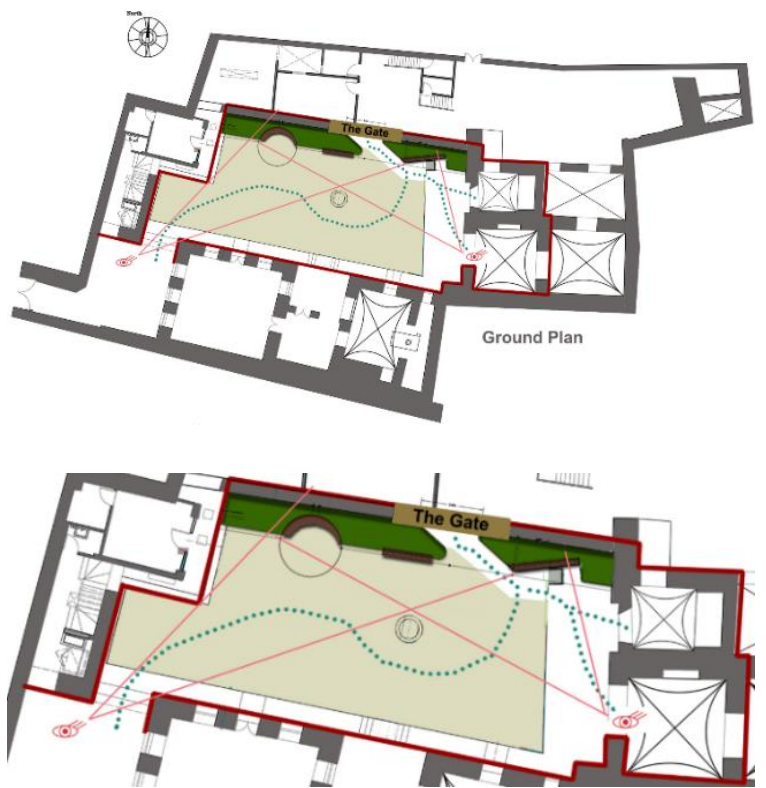

Figure 13: shows the movement circulation of users inside the courtyard, and the focal visual points for the bustan. [Source: Researchers]

\subsection{The Bustan, the House and the Courtyard}

One of the main concerns in the design of the bustan was how much area which should it occupies from the courtyard. It covers approximately $13.5 \%$ of the courtyard area, which is considered to be a large area comparing to the reduced size of the courtyard. However, the placement of it along the northern solid wall meant to use effectively a dead space that was seldom integrated with any activity beside providing seats, especially that it was constantly exposed to direct sun. The criteria for choosing its current area was well thought to preserve the identity of the ratio of the historic courtyard to the built fabric while adding a missing aspect to it which is the greeneries. It does not obstruct the movement in the courtyard, but rather enhances mobility towards various functions such as exhibitions, workshops, and other community activities. (Figure 14 and 15) 


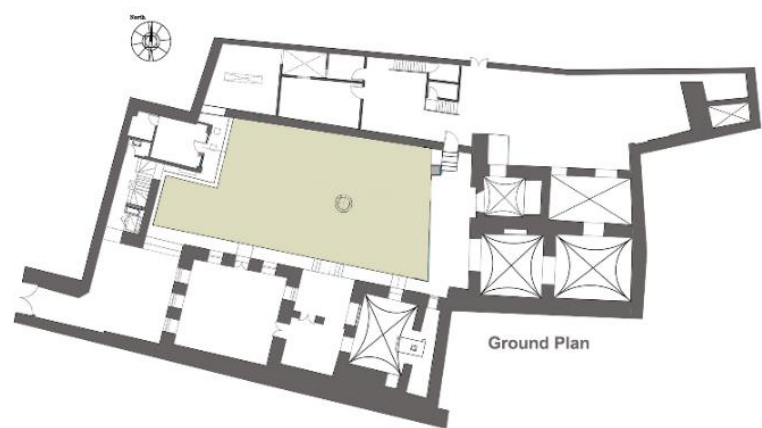

Figure 14: The courtyard without the bustan. [Source: Researchers]

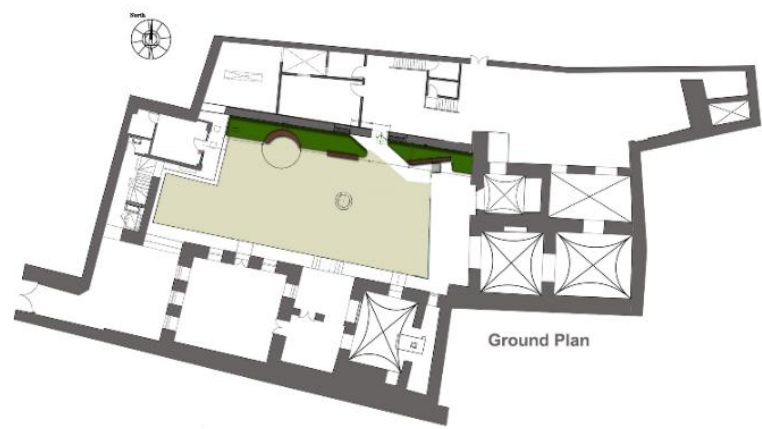

Figure 15: The area and position of the bustan inside the courtyard. [Source: Researchers]

\subsection{Re-Integrating Access}

The design took into consideration the future plans that are envisioned for the land located north of the sold wall and that will be accessed throughout the reconstructed historic gate. (Figure 16) A previous door located at the northeastern corner provided the only access to this area was blocked and replaced with a window. Accessibility was shifted to the main new historical Gate in order to accentuate its existence and provide an essential function to it. This reshuffling of roles and locations enhanced mobility and offers a larger space to be integrated into the bustan. (Figure 17)

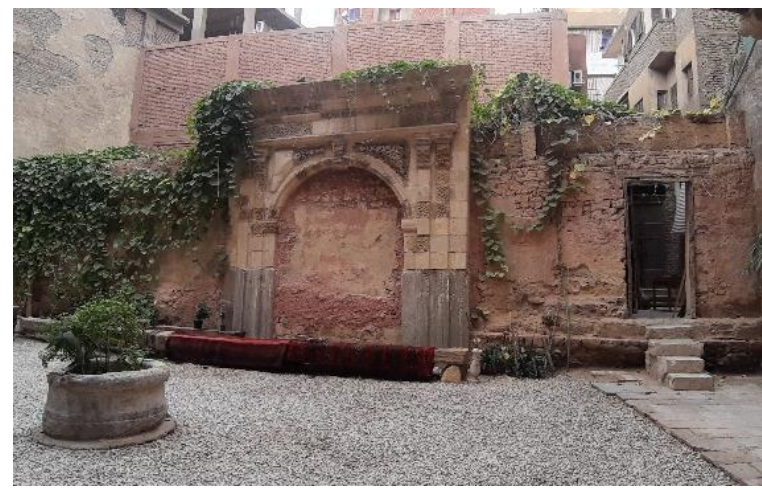

Figure 16: The initial old historical Gate condition, and the existing entrance and stairs.

[Source: Researchers]

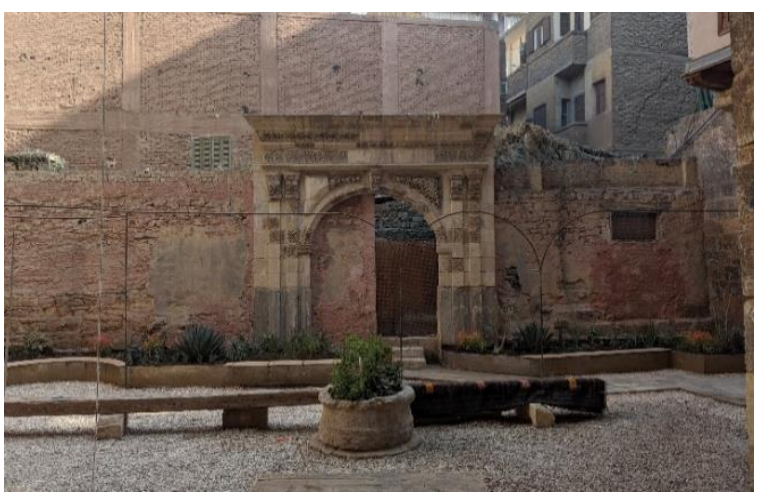

Figure 17: the new entrance for the background area within the historical gate, stairs after repositioned the door. [Source: Researchers]

In that respect, the bustan was designed to fit the future plan of Bayt Yakan, as it will sustain the provisioned changes in this area of the house. (Figure 17) The gardens flanking the historic gate provided an organic procession towards it throughout a pathway that approaches it in an angular way. This allows the users to grasp as much as possible the details of the gate and understands the message behind its reconstruction in the courtyard of Bayt Yakan: keeping shreds of valuable attributes is a way to preserve the memory of the area and the city.

\subsection{Respecting Values}

Many historical and social values exist in the courtyard of Bayt Yakan as it is the core for most of the social activities in the neighborhood. The garden main purpose is to enhance these values and contribute positively to interpret the attributes of these values and create an interactive atmosphere for the visitors and the community without overshadowing the historical values of the courtyard and the historic house. The addition of the bustan followed the conservation principles set for additions in the 1964 Venice charter, which is a document that is still respected in conservation practices. [11] Moreover, the bustan is a visualization of the environmental principles of the Valletta charter of 2011. [6] It was then necessary to take all related conservation considerations in the design such as the choice of materials, colors, texture, proportions, lighting, and electrical fixture and how to integrate all of them with the historic context. The following are detailed assessment of how those parameters were met in the various design aspects:

a) The proportion of the historical gate and the bustan

The bustan was conceived as a subtle addition yet designed to highlight the positioning of the gate as described earlier. The bustan and the gate are both 
enhancing the interpretation of each other, for the bustan is designed as a frame to the gate. The green species were carefully selected to proportionally fit in the context and not to distract attention from the interesting and valuable elements in the courtyard. (Figure 18)

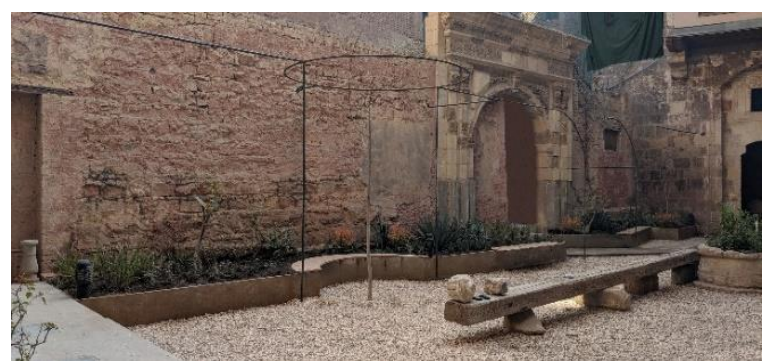

Figure 18: The historical gate and the bustan, [Source: Researchers]

\section{b) Colors and Texture}
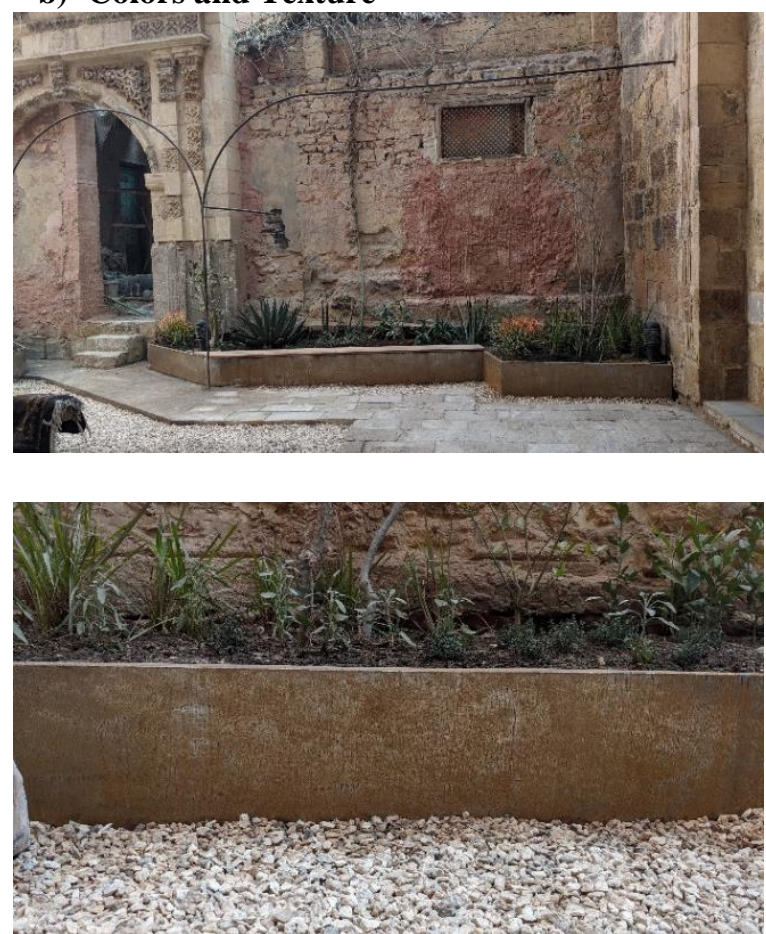

Figure 19: Rusting finishes of the steel

[Source: Researchers]

The finishing color and texture have great effect in affecting the perception of the historical environment. The concept is for any new addition not to capture attention, but to blend in homogeneously with its surrounding while respecting the historical values. Those conservation principles are well detailed in the 1964 Venice charter. Choosing the rusting effect to the steel (corten steel) selected for the raised walling of the bustan made the material unperceivable while maintaining the longevity and the thinness required.
(Figure 19) It was a big challenge to make the steel rusting rapidly and as shown in Figure 20 water was sprayed on after removing the galvanized layer for the acceleration of the rusting process. The steel was insulated to stop the rusting to persist and to prevent corrosion to damage the material.
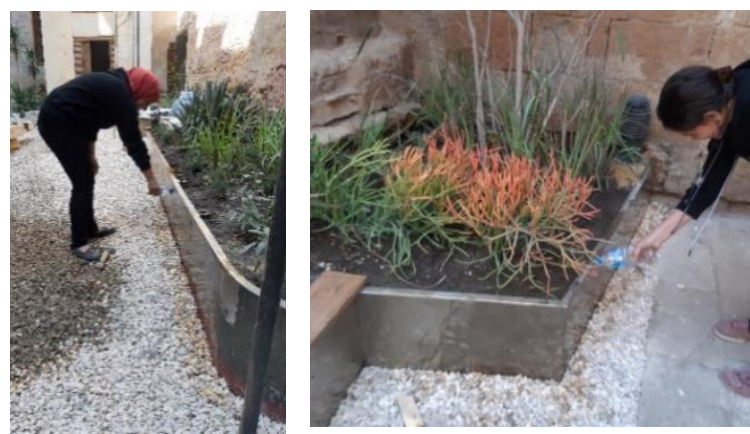

Figure 20: Spraying water to accelerate rusting. [Source: Researchers]

\section{c) Benches Color and Materials}

Choosing the unpolished teak wood has been successful with the reference of the texture, color, and outdoor characteristics required in the 3 bustan. (Figure 21) The wooden type assured longevity for outdoor exposure.

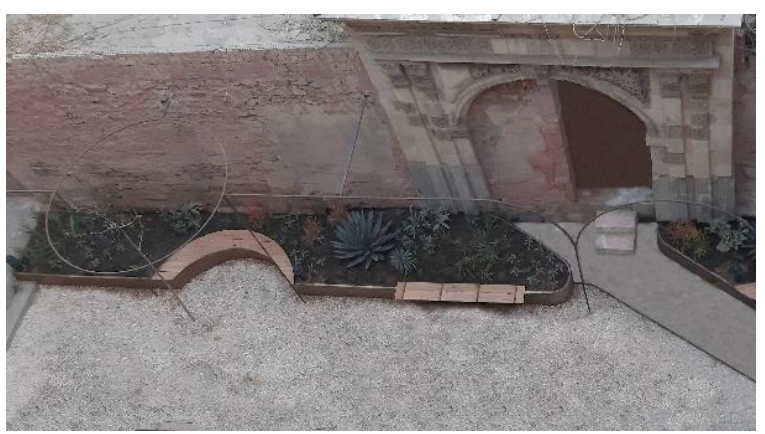

Figure 21: Teak wood color and texture in reference to the surrounding context. [Source: Researchers]

\section{d) Basalt Bases}

Bustan garden is designed and executed to respect the nature of the historical context, therefore, the base material which used in fixating the steel columns of the coulisse was made in basalt large bases to ensure the steel loads distribution and good stabilization while avoiding the use of concrete within the historical context. Those basalt bases are traditionally used to carry pintles of heavy doors. One of those traditional bases is exhibited in the courtyard of Bayt al-Razzaz for the use of academics and researchers. Four basalt bases were specially made and drilled through for the steel rods to be secured in them. The bases were well-grounded in compacted soil for stabilization. (Figure 22 and Figure 23) 


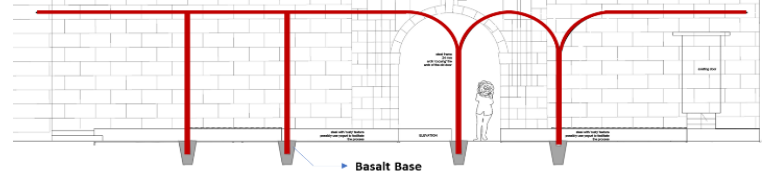

Figure 22: The detailed drawings for Basalt bases and steel column fixation. [Developed by: Researchers]
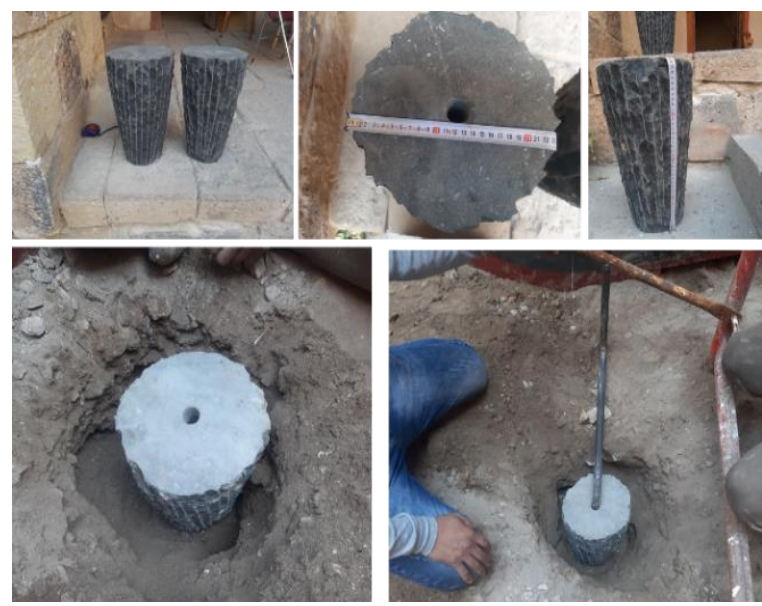

Figure 23: Basalt bases during the implementation [Source: Researchers]

\section{e) Existing Stairs}

The preexisting stair as shown in Figure 24 has been one of the obstacles in the execution of the extended steel-sheets walling. Therefore, the suitable solution was to bend the steel sheets in the exact dimensions to fit with the stairs where they overlap to extend the planting area without having to break this section of the stairs. (Figure 25)

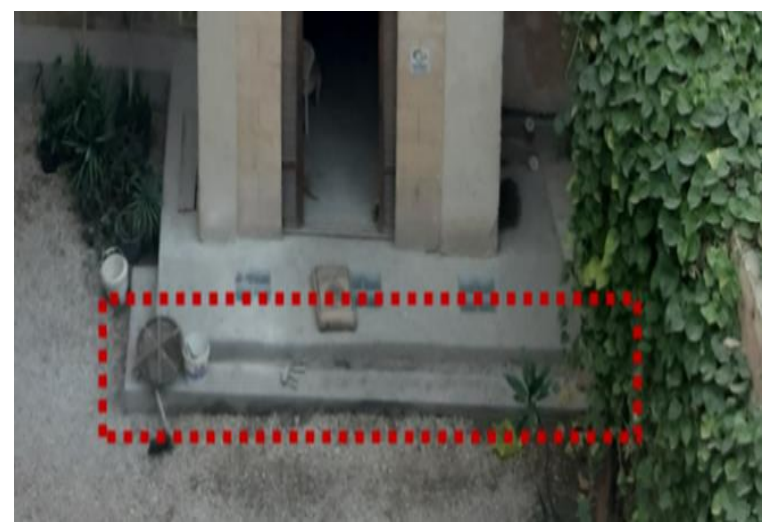

Figure 24: The preexisting stairs before installing the al-Bustan. [Source: Researchers]
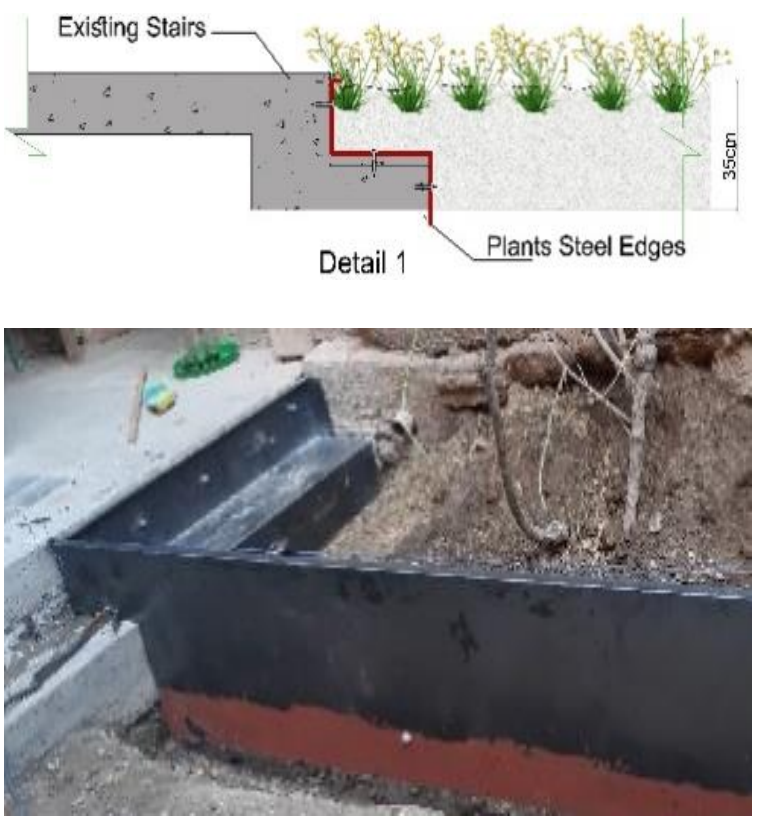

Figure 25: Installing the steel edges of the stairs.

[Source: Researchers]

\section{f) Respecting the underground tunnel}

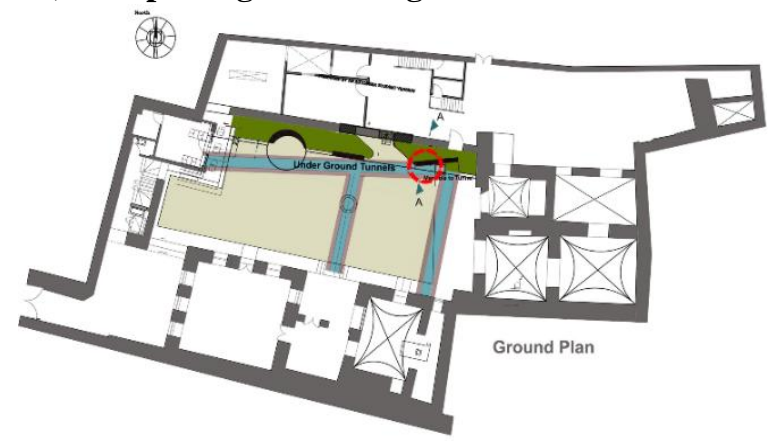

Figure 26: shows the points and areas that al-Bustan meets with the underground tunnels.

[Source: Researchers]

The fixation of the steel columns with their basalt bases into the ground was challenged due to the existence of sub-surface tunnels, historically used for sewerage. Those tunnels are running, as shown in the plans, under some of the basalt bases as well as one of the steel walling planks. (Figure 26) The steel poles had to be bent to slightly shift the location of some of the bases not to harm the structures of the tunnels. Similarly, the steel planks were bent following the profile of the tunnel in a way that will prevent it from loading any pressure onto the underground tunnel. (Figure 27) 

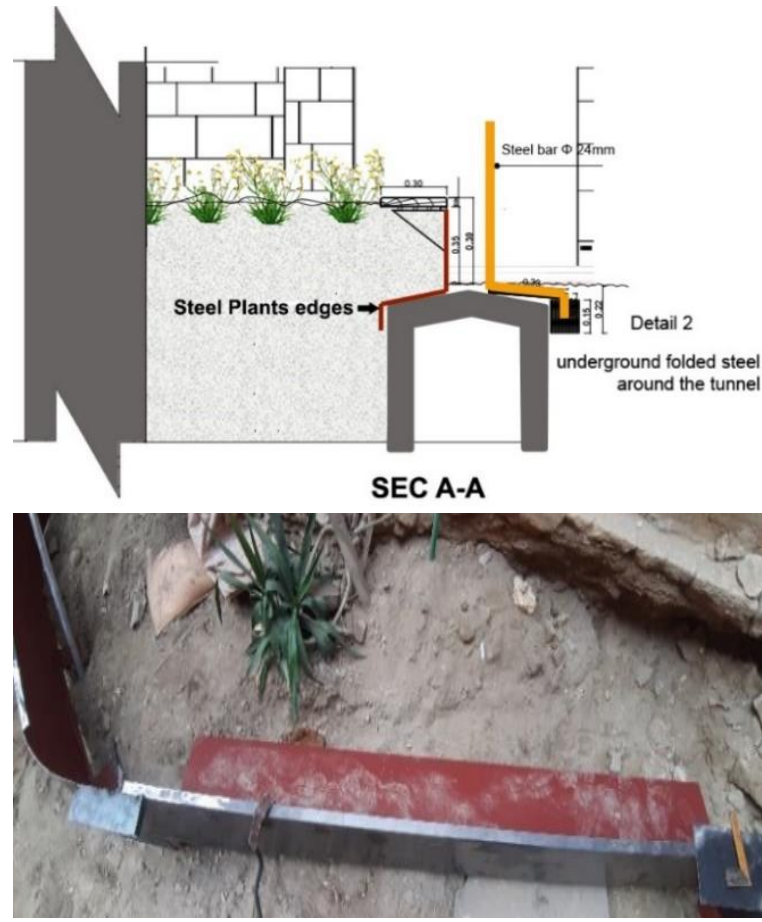

Figure 27: Detailed drawing for the bent steel column and planted area steel edges and how they had installed with the reference to the underground tunnel, second photo for the bent steel edges during its implementation. [Source: Researchers]

\section{g) Lighting}

A theatrical effect was created by the lighting placed in specific positions and the type of directed lighting with proper light exposure create this dramatic light and shadows effects that was enhanced the plants' shape on the background solid wall. (Figure 28)
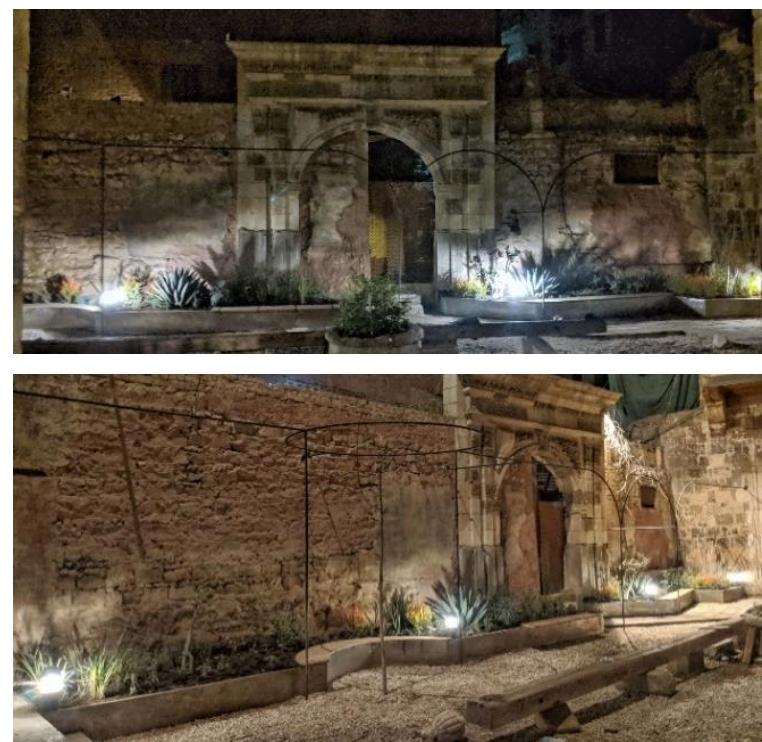

Figure 28: Dramatic light and shadows with the plants' shape on the historic wall and gate.

[Source: Researchers]
Connecting those lighting units to the power was not an easy task as all wirings need to be secured, isolated from any water, and hidden for aesthetic purposes and for not disfiguring the historical context. The solution was to bypass well-isolated wires through the underground tunnel and allows them to emerge to the surface wherever a lighting unit is needed. This solution allowed accessibility to easily reach the main electrical panel board that is located in the basement. (Figure 29 and 30).

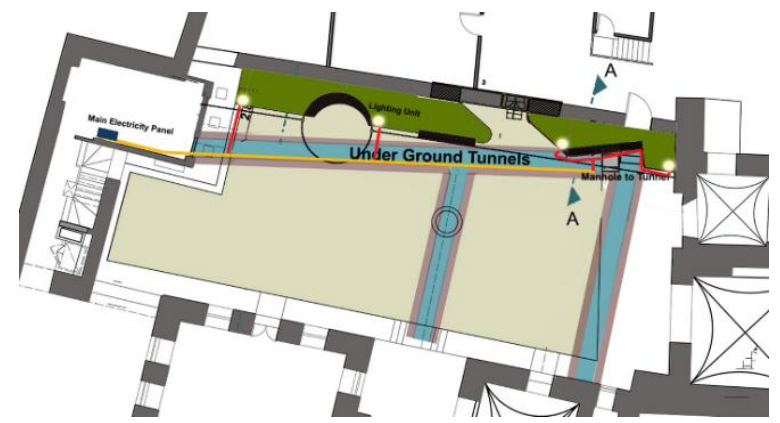

Figure 29: how the electrical fixture was done through the underground tunnel in order to a special lighting for al-Bustan. [Source: Researchers]
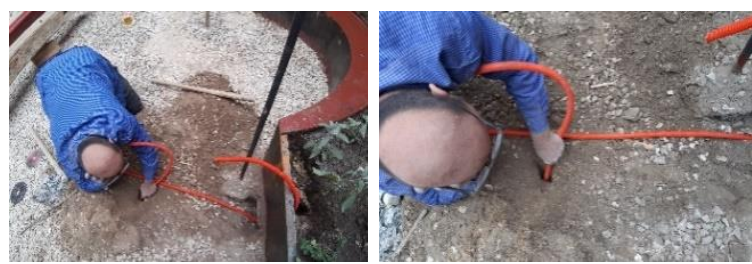

Figure 30: The electrician passes the wire through the plant's soil to the underground tunnel during the implementation process. [Source: Researchers]

\subsection{Adaptation of Plants to the Environment}

The process of selecting the plants' types was done carefully and took many visits to multiple nurseries around Cairo. As a result, the selections were narrowed down to edible and medicinal vegetations that can withstand the high temperature and humidity of Egypt [12]. Another parameter was to select plants that are easily planted and maintained by the local community so that they can be transplanted in their other roof gardens and balconies. Examples of the selected plants are rosemary, cumin, ginger, hibiscus, mint, sage, and thyme. In addition, some cactus were selected for the dry and high temperature of the garden location so it would be durable, and they mark fixed long-term points in the bustan, and provide some aesthetic features. For those Agave Angustofolia, Adenium Obesium, Euphorbia Tirucallim, and Pulmeria Alba were selected. [13] (Figure 31) All together they have formed the current bustan in Bayt Yakan which was highly praised by the community and the regular visitors of the house. 


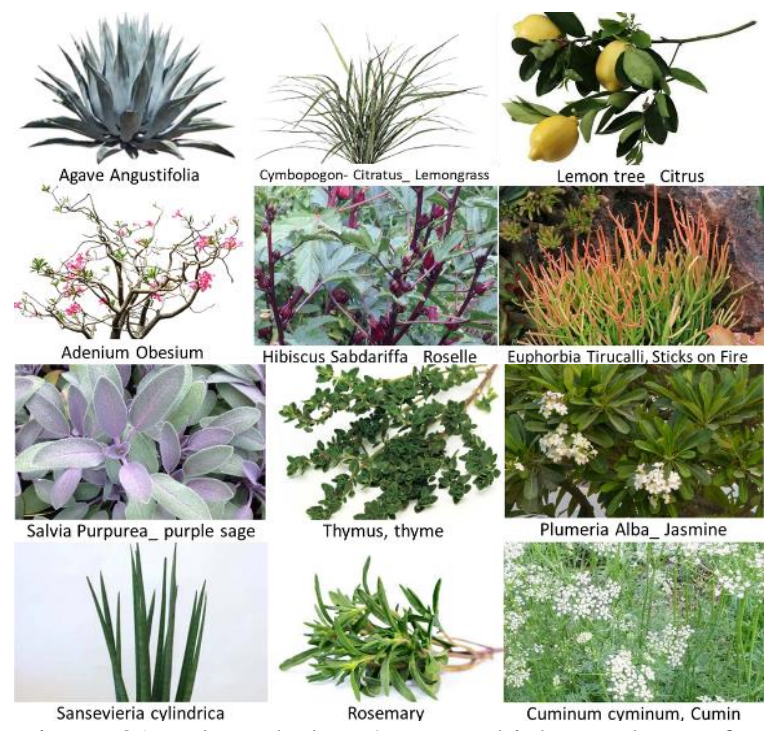

Figure 31: selected plants' types which are chosen for the bustan [Source: [10, 12]]

\section{The community participation in planting}

In order to have the members of the community feel that the bustan is their own, they were consulted in a workshop to enhance and select the design, as well as to select the types of vegetation and trees. That was a key for familiarizing and explaining the idea of the bustan and the hopes anticipated from it. The objective was to have the community protecting, respecting, and taking care of it. (Figure 32) Moreover, the community participated in the process of planting so that they would learn how simple and easy the process is and learn from the horticultural expert that was consulted the techniques of watering, seeding, fertilizing, trimming, and transplanting. This made them able to duplicate these easily at their home with some basic tools that they can borrow from Bayt Yakan.
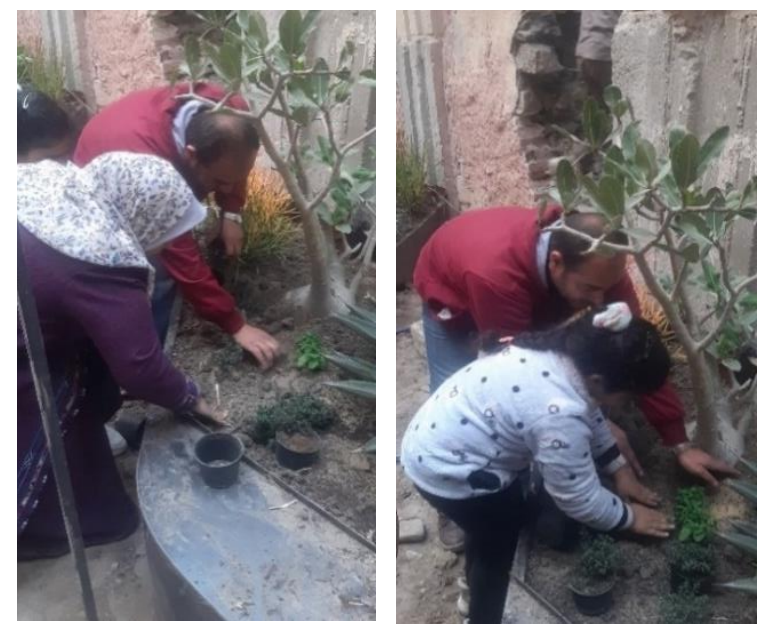

Figure 32: The community of Bayt Yakan during planting the bustan. [Source: Researchers]

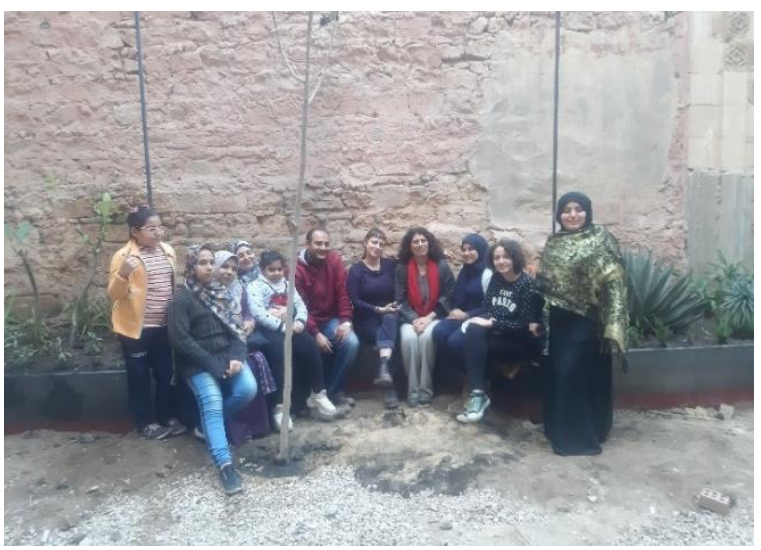

Figure 33: The designer, Lada, Researchers, and the plant Engineer with the community of Bayt Yakan setting and interact with the bustan.

[Source: Researchers]

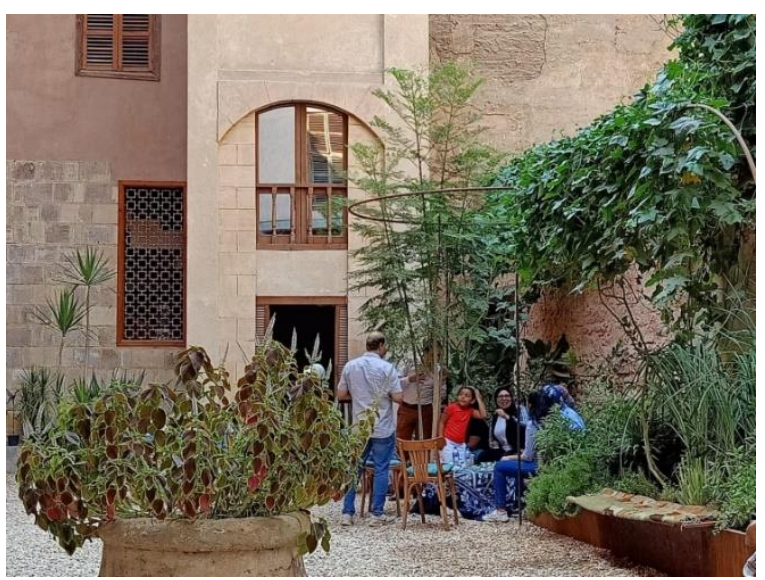

Figure 34: The bustan as it stands and enjoyed by the local community. [Source: Researchers]

\section{Conclusions and Recommendations}

The research adopts a green corridors strategy with all its effectiveness factors in socio-culture, economic, and environmental aspects as promoted by international ICOMOS and UNESCO charters. It represents bustan Bayt Yakan as the seed for how to integrate interconnected pockets to form the prospective green corridors within the historic urban fabric. Sustainable developments in historic contexts and regeneration of the traditional ecosystem are the objectives here that are hoped to be adopted by the local government to upscale the impact and to enhance the management of the historic city. This research demonstrates that the process of integrating the community for a good cause and for a potential sustainable development in Al-Darb Al-Ahmar area is not too difficult to attain. The local community should adopt the idea of preserving the heritage and enhance their belonging to their historical contexts as well as respecting and interpreting all its attributes and values. 
Besides the long-term objectives for the bustan, the research promotes the following:

a) For Environmental aspect:

- Encouraging the local community to duplicate the bustan in their rooftops or balconies to propagate the greeneries required within the historical fabric. This will activate and enhance the environment of the traditional urban ecosystem and improve the climatic conditions and thermal comfort not only inside buildings but also at the scale of the urban fabric.

- Promoting a new study to assess the impact of the integration of the bustan in the courtyard of Bayt Yakan and examine its effect on the microclimate conditions in indoor spaces.

b) For Economic aspect:

- Encouraging the local community to plant their own garden and provide them with seeds from the bustan Bayt Yakan, that will positively affect their income and their standard of living by producing and use the products in culinary and medicinal treatments.

c) For Social Aspect:

- Raising awareness of the community to the importance of integrating garden within the contemporary fabric with respect to the local historic values. Similar to the case of the one of Bayt Yakan, prospective bustans of historic Cairo shall acquire a new creative role to bring the local community together, assure for sustainable development, while preserving the intrinsic values of the historic fabric.

\section{Acknowledgments}

- Researchers were responsible for implementing al-bustan in Bayt Yakan and participated along with the local community with Bureau Lada in the design process.

- This paper was presented in the "Third International Conference of Faculty of Engineering, Menoufia University (Eleventh Conference of Sustainable Environmental Development), which was held in Sharm El Sheikh, Egypt from the $27^{\text {th }}$ of September to the $1^{\text {st }}$ of October 2020.

\section{References}

[1] S. Attia, "The role of landscape design in improving the microclimate in traditional courtyard-buildings in hot arid climates," in PLEA2006 - The 23rd Conference on Passive and Low Energy Architecture, Geneva, Switzerland, 2006.

[2] M. LAFFAH, "The courtyard garden in the traditional Arab house," Courtyard Housing. Past, Present, and Future, no. 13, pp. 208-219, 2006.

[3] A. Foruzanmehr, "nergy efficiency and sustainability in vernacular architecture of Iran: Traditional design, construction methods and passive strategies," 2006.
[4]" Bayt el Suhaymi: The House of Suhaymi, Khan el Khalili, Cairo.," 2006. [Online]. Available: http://www.touregypt.net/featurestories/baytsuhaym i.htm. [Accessed 12 March 2020] .

[5] A. El Habashi, O. Al Hinawy and R. Reyad, "Assessing the Environmental Performance of Historic Cairo: Preserving Valurs and Improving Energy Efficiency," in Green Heritage International Conference: Chance- Change- Challenge, 6-8 March 2018, 2018 .

[6] I. G. A. "The Valletta Principles for the Safeguarding and Management of Historic Cities, Towns and Urban Area," ICOMOS, 2011.

[7] A. El-Habashi, The 6th international Workshop for Enhancement of Egypt- Japan Joint Research Projects in Egypt, 2019.

[8] N. Ramírez and A. El Habashi, "reGREENeration of Historic Cairo," The Journal of Public Space, vol. 5, no. 1, pp. 51-74, 2020.

[9]

$$
\begin{aligned}
& \text { ي. ه. محمود، "تقييم الأداء البيئي للبيوت ذات الأحواش }
\end{aligned}
$$

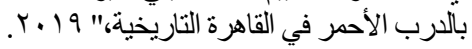

[10] B. LADA, "Bustan: Planting, Scheme, details, visuals," 2019.

[11] I. Committee, "International Charter for the Conservation and Restoration of Monuments and Sites: Venice Charter 1964," in IInd International Congress of Architects and Technicians of Historic Monuments, Venice, 1965.

[12] L. E. S. E. Masry, A PLANT GUIDEBOOK FOR AL AZHAR PARK AND THE CITY OF CAIRO: VOL. 2 .

[13] F. Hallé and É. Patriarca, Atlas of Poetic Botany, MIT Press, 2018. 